\title{
Multifocal follicular carcinoma of thyroid following radiotherapy for Hodgkin's disease
}

\author{
FIONA NICOL $\dagger$ \\ B.Sc., M.R.C.P.
}

KATHRYN M. MCLAREN*

B.Sc., M.B., Ch.B.

\author{
ANTHONY D. ToFT $\dagger$ \\ M.D., F.R.C.P.E. \\ University Departments of $\nmid$ Medicine and *Pathology, Royal Infirmary, Edinburgh EH3 9YW
}

\begin{abstract}
Summary
A 21-year-old white male developed multifocal follicular carcinoma of the thyroid gland 17 years after receiving neck irradiation (3000 rad) for Hodgkin's disease. The tumour was unique in that follicular carcinoma has not previously been reported as having a multifocal origin, even after high dose radiotherapy.
\end{abstract}

\section{Introduction}

The occurrence of thyroid cancer after irradiation of the neck has been recognized for 30 years (Duffy and Fitzgerald, 1950). This has usually followed low dose radiotherapy for conditions such as thymic enlargement, acne vulgaris and tuberculous adenitis (Paloyan and Laurence, 1978; Hempelmann et al., 1967). High dose radiotherapy of the neck as employed in Hodgkin's disease has been considered ablative rather than carcinogenic (Greenspan, 1974), but recently there have been cases reported of papillary or mixed papillary-follicular carcinoma following treatment for Hodgkin's disease (Bryda and Ward, 1980). A case believed to be unique is reported in which follicular carcinoma with multifocal origin developed after high dose irradiation for Hodgkin's disease.

\section{Case report}

A 21-year-old white male was found to have a firm diffuse goitre not associated with lymphadenopathy and without a bruit at a routine lymphoma follow-up clinic. He was asymptomatic. In 1964, when 4 years old, he presented with cervical lymphadenopathy. Lymph node biopsy was consistent with Hodgkin's disease. At that time he received a fractionated course of radiotherapy to the anterior and posterior head and neck. The total dose of $3000 \mathrm{rad}$ was given over 3 weeks as 16 daily fractions of $187 \mathrm{rad}$.
At review he appeared clinically euthyroid, $\searrow$ confirmed by a plasma total thyroxine level of $88 \vec{\infty}$ $\mathrm{nmol} / \mathrm{l}$ (normal $50-150 \mathrm{nmol} / \mathrm{l}$ ) and a plasma thyrotropin (TSH) level of $2 \cdot 1 \mathrm{mu} . / 1$ (normal up to 음 $5.7 \mathrm{mu} . / 1)$. Antibodies to thyroid microsomes and thyroglobulin were not present in the serum. The ${ }^{131}$ I uptake by the thyroid gland at $4 \mathrm{hr}$ was $33 \% \frac{\mathrm{O}}{3}$ (normal 10-40\%) and a $99 \mathrm{mTc}$ scan showed a patchy uptake of isotope by the goitre. In view of $\vec{\varnothing}$ the possibility of lymphoma of the thyroid gland ang ? the previous neck irradiation he was referred fö open biopsy. At operation the gland had the gross appearance of a multinodular goitre and partial thyroidectomy was performed.

The resected right and left lobes of the thyroid $\frac{\mathrm{O}}{\mathrm{Q}}$ measured overall $6 \times 5 \times 2 \mathrm{~cm}$ and weighed $27 \mathrm{~g}$. Both lobes were multinodular in appearance, the $\frac{\rho}{3}$ nodules varying in size, with a maximum diameter of $1 \mathrm{~cm}$. The thyroid capsule was macroscopically intact without evidence of invasion by the subjacent thyroid parenchyma.

Microscopic examination revealed loss of normal lobular architecture. There was loss of normal 3 acinar differentiation, with trabeculae and aggregates of cells growing in a closely apposed manner in 3 solid cellular foci. The peripheral cellular nodules 0 expanded and compressed the thyroid capsule, but did not infiltrate the latter in many blocks examined. There was no evidence of vessel wall invasion by thyroid epithelial cells. The appearances were those $N$ of a follicular carcinoma of thyroid (Fig. 1), with an $N$ apparent multifocal growth pattern.

Postoperatively $50 \mathrm{mCi}$ of ${ }^{131} \mathrm{I}$ was given in order $\mathrm{W}$ to ablate the thyroid remnant. Six weeks later when the plasma TSH level was $>90 \mathrm{mu}$./l whole body $\stackrel{\circ}{\complement}$ scanning $24 \mathrm{hr}$ after the oral administration of $1 \mathrm{mCi} \stackrel{\varnothing}{\Phi}$ ${ }^{131}$ I showed no evidence of thyroid remnant or $\stackrel{+}{+}$ of functioning metastases. Thyroxine suppressive therapy was commenced. 


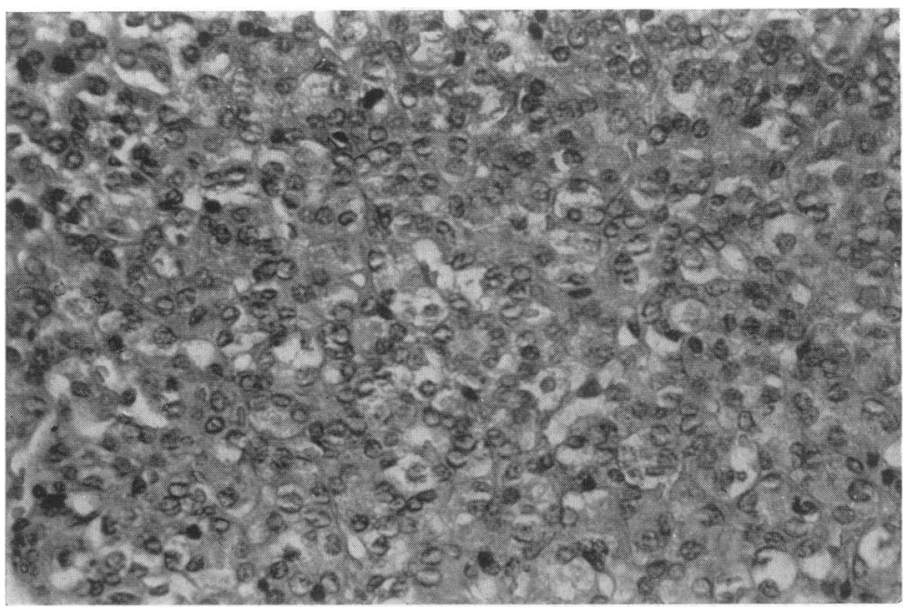

Fig. 1. Follicular carcinoma of thyroid. The epithelial cells are large and pleomorphic, with focal irregular follicle formation. $(\mathrm{HE}, \times 320)$.

\section{Discussion}

The usual type of thyroid carcinoma reported after radiotherapy is papillary or mixed papillary follicular carcinoma (Frank and Ashcraft, 1980; McDougall et al., 1980). This case is unique since follicular carcinoma after radiotherapy with multifocal origin has not been reported before. Since multinodular thyroid hyperplasia with dysplastic features is a well recognized post-irradiation feature, it is surprising that progression to malignancy of a pure follicular nature is so rare.

The development of thyroid carcinoma after high dose radiotherapy was thought to be rare (Maxon et al., 1977) but is being increasingly recorded (Frank and Ashcraft, 1980; McDougall et al., 1980). Children and adults are equally susceptible (Schimpff et al., 1980). The interval between irradiation and tumour development is 3-30 years. With the improved prognosis of Hodgkin's disease in recent years it is reasonable to expect that more cases of thyroid cancer will be detected in future. An increased awareness of the possiblity of thyroid cancer developing many years after irradiation for Hodgkin's disease may lead to earlier diagnosis and successful treatment of the secondary malignancy, and it is recommended that follow-up for all these patients is continued long-term.

\section{Acknowledgments}

We are grateful to Drs G. L. Ritchie and A. C. Parker of the Edinburgh Lymphoma Group for referral of this patient for further evaluation.

\section{References}

BRYDA, S. \& WARD, J.A. (1980) Thyroid carcinoma after radiation for Hodgkin's disease. Annals of Internal Medicine, 93, 146.

Duffy Jr, B.J. \& Fitzgerald, P.J. (1950) Cancer of the thyroid in children: a report of 28 cases. Journal of Clinical Endocrinology and Metabolism, 10, 308.

Frank, H.J.L. \& AshCRAFT, M.W. (1980) Thyroid carcinoma after radiation for Hodgkin's disease. Annals of Internal Medicine, 93, 145.

GreensPan, F.S. (1974) Thyroid nodules and thyroid cancer. Western Journal of Medicine, 121, 359.

Hempelmann, L.H., Pifer, J.W., Burke, G.J., Terry, R. \& AMES, W.R. (1967) Neoplasms in persons treated with $X$-rays in infancy for thymic enlargement. A report of the 3rd follow-up survey. Journal of the National Cancer Institute, 38, 317.

McDougall, I.R., Coleman, C.N., Durke, J.S., Saunders, W. \& KaPlan, H.S. (1980) Thyroid carcinoma after high dose external radiotherapy for Hodgkin's disease. Report of three cases. Cancer, 45, 2056.

Maxon, H.R., Thomas, S.R., Saenger, E.L., Buncher, C.R. \& KereiAKES, J.G. (1977) Ionizing irradiation and the induction of clinically significant disease in the human thyroid gland. American Journal of Medicine, 63, 967.

Paloyan, E. \& Laurence, A.M. (1978) Thyroid neoplasms after radiation therapy for adolescent acne vulgaris. Archives of Dermatology, 114, 53.

SchimpfF, S.C., Diggs, C.H., Wiswell, J.G., Salvatore, P.C. \& WierniK, P.H. (1980) Radiation-related thyroid dysfunction: implications for the treatment of Hodgkin's disease. Annals of Internal Medicine, 92, 91. 